\title{
Construction of digital operation and maintenance system for new energy power generation enterprises
}

\author{
Zhang Wenyu ${ }^{1, \text { a }}$, Liu Hongyong ${ }^{1}$, Xu Xiaochuan ${ }^{1}$, Li Ming $^{1}$, Ren Weixi ${ }^{1}$, Ma Buyun ${ }^{2}$, Ren jie ${ }^{1}$ and Song Zhenyu ${ }^{1}$ \\ ${ }^{1}$ Department of Production and Technology, Wind and Solar Power Energy Storage Demonstration Station Co. Ltd State Grid, \\ Zhangjiakou, China \\ ${ }^{2}$ Department of Science and Technology, Wind and Solar Power Energy Storage Demonstration Station Co. Ltd State Grid, Zhangjiakou, \\ China
}

\begin{abstract}
In view of the current increasing new energy installed capacity and the frustration in outputting clean electricity due to limited channel capacity, the new energy intelligence operation system based on big data platform technology, joint power monitoring technology and large-scale energy storage power station integrated with control technology is adopted through unified modeling and communication protocols, so as to solve the problems in information interaction and unified controlling for manufacturers of multiple wind turbine, PV, storage equipment , and varieties of equipment types.So, by structuring the power-grid friendly wind power plant, photovoltaic power plant and the energy storage power plant, and taking the "five ascension" measures can greatly reduce the workload of the staff, improving the working efficiency and the economic benefits of the enterprise greatly, meanwhile it also provide new methods, new measures and new ideas for other new energy power plants, to realize the improving of the comprehensive benefits and social value.
\end{abstract}

\section{Introduction}

With the continuous development of new energy industry, the installed capacity of new energy is increasing year by year. At the same time, our biggest concern is how to enhance the security and stability capacity of new energy plants, improve the generation level of new energy plants and improve the economic efficiency of power generation enterprises under the conditions of limited access to the power grid, power market reform and rapid development of the energy Internet. For new energy plants represented by wind turbine, photovoltaic and energy storage, lean management not only plays a certain demonstration role in the management of all new energy plants affiliated to the company, but also plays a significant demonstration role in the domestic new energy industry.

\section{Implementation significance function}

The establishment of this new energy power station is based on the practical experience of the operation and maintenance system of new energy power generation enterprises with digital management. In order to cope with the limited power generation caused by the annual increase of new energy installed capacity and insufficient power supply channel capacity, the power plant adopts the intelligent operation and maintenance technology of new energy based on big data platform, high-precision windsolar power prediction technology, panoramic monitoring

\footnotetext{
${ }^{\mathrm{a}}$ Corresponding author: zhang.wyu@hotmail.com
}

technology of joint power generation and integration and regulation technology of large-scale energy storage power station. It solves the problem of information interaction and unified coordination control of multiple wind turbine, photovoltaic, energy storage equipment manufacturers and multiple equipment types by establishing the model and the method of unified equipment communication protocols. So, by structuring the power-grid friendly wind power plant, photovoltaic power plant and the energy storage power plant, throughing the four-in-one with the smart substation, an intelligent operation and control mode integrating the operation mode of generation, transmission, transformation and distribution can greatly reduce the workload of the staff, improving the working efficiency and the economic benefits of the enterprise greatly, meanwhile it also provide new methods, new measures and new ideas for other new energy power plants, to realize the improving of the comprehensive benefits and social value.

\section{Main implementation methods}

The "five improvement methods" refers to the improvement of the equipment monitoring level, the ability to make work plans, the ability to diagnose and warn equipment faults, the ability to improve comprehensive intelligent control, and the ability to improve the level of energy storage application technology, which has comprehensive improved the management level in multi-level and multi-channel. The proposal of "five 
improvement methods" on the data-based management of power generation operation and maintenance also explores and practices the standardization and digitization construction of new energy power generation management. It effectively improves the power generation capacity of the power plant. At the same time, it also optimizes the management mode of the power station, reducing the loss of the station, comprehensively improving the efficiency of the enterprise. Besides, it promotes the healthy development of the new energy power generation industry, to help to realize the safe, reliable and efficient operation of new energy power plant.

\subsection{Digital construction of equipment monitoring}

The monitoring system of the power station consists of three levels: dispatching analysis layer, monitoring layer and equipment layer. Dispatching analysis layer is the superior dispatching center and a bridge between the power generation system. On the one hand, it builds open consistent grid model of combined power generation system to provide the superior dispatching operation analysis support, on the other hand, as the control center of the whole system of intelligent analysis and decisionmaking, it also can implementation coordination control the wind power, photovoltaic and energy storage. The monitoring layer of the station realizes the individual monitoring of each subsystem, uploading the operation information of each device in real-time, receiving the control instruction from the joint control system at the same time. After decomposition, the wind turbine, photovoltaic inverter and energy storage control unit are sent to the equipment layer.

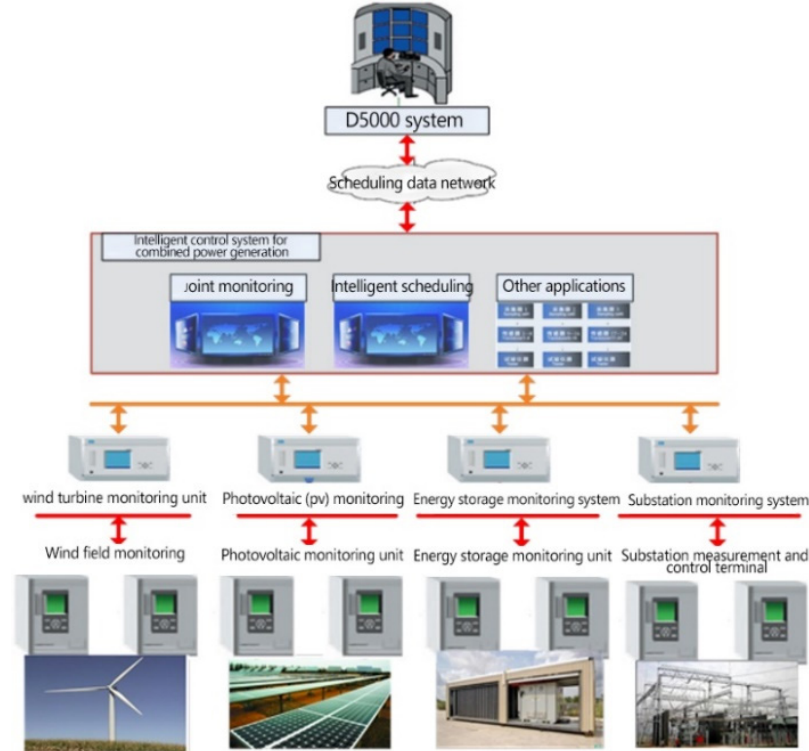

Figure 1. Schematic diagram of panoramic monitoring system

The comprehensive monitoring of the power station is carried out in a hierarchical way, including four layers: measuring point layer, equipment layer, station layer and panorama layer. On the equipment layer, all kinds of remote information and telemetry information of wind turbine, photovoltaic inverter, energy storage unit are organized to implement detailed monitoring in the same monitoring screen. The important information of all the equipment in the station is integrated into one picture, which constitutes the overall monitoring of the specific station equipment. Panoramic surveillance technology is a visualization technology based on multi-screen fusion. It correlates the key data of wind turbine, PV and energy storage with the existing relationship, and combines and displays with many pictures. Through "information linkage switch" and "advanced graphics drive engine", not only the consistency and integrity of the display information is maintained, but also the multi-dimensional display of the overall running state of the demonstration project is provided.

\subsection{Make a systematic annual plan}

By proposing the main factors of the whole process management in five aspects of safety, efficiency, stability, benefit and cost, the corresponding performance indicators are formulated for the production work of the power station. At the beginning of the year, compile and publish annual production indicators and key work in all aspects, so as to make unified arrangements for the work of production safety this year in this way. Organizing and making monthly production plan according to annual production plan at the beginning of each month. Through organizing and carrying out the review meeting of the transportation inspection plan, the weekly work plan is further refined by considering the factors such as professional inspection tour, elimination arrangement and daily maintenance. By formulating the production operation and maintenance budget, strengthening the daily cost management process, reducing production consumption, formulating the power generation plan in combination with scenic resources, and dividing the annual power generation plan into months according to the equipment maintenance, so as to ensure the completion of the annual power generation plan and increase the inputoutput ratio.

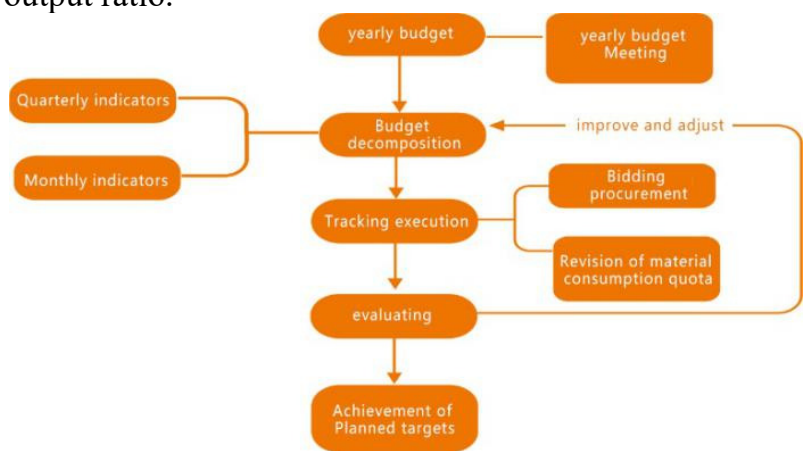

Figure 2. Flow chart of production plan

For new energy stations, the main factors influencing the capacity is the equipment maintenance. So for the power outage overhaul planning is very important, both annual outage overhaul plan and monthly, weekly maintenance plan, the traditional power outage overhaul plan tend to "wind-poor period" and "wind-rich period" as the important basis of power outage overhaul plan. The maintenance plan without fully considering the power within the planning date will have power problems more or less. On one hand, under maintenance planning, cannot achieve flexible adjustment; On the other hand, the 
rationality of the reported plan is not evaluated. Therefore, the power station puts forward a flexible power failure maintenance plan with the function of prediction and evaluation, so as to achieve the goal of minimum power loss caused by power failure maintenance and the highest economic benefits of power generation.

Forecast scenery integrated power system and the production management system through taking data interaction, through operations in the region more data sharing, optimization of regional weather forecast, operations of the facility, equipment, the implementation power prediction data calibration and reference, and forecast data through the scenery power prediction system, determine the corresponding output the minimum time period, as a power outage overhaul plan mobile time, establishing perfect operational maintenance plan.

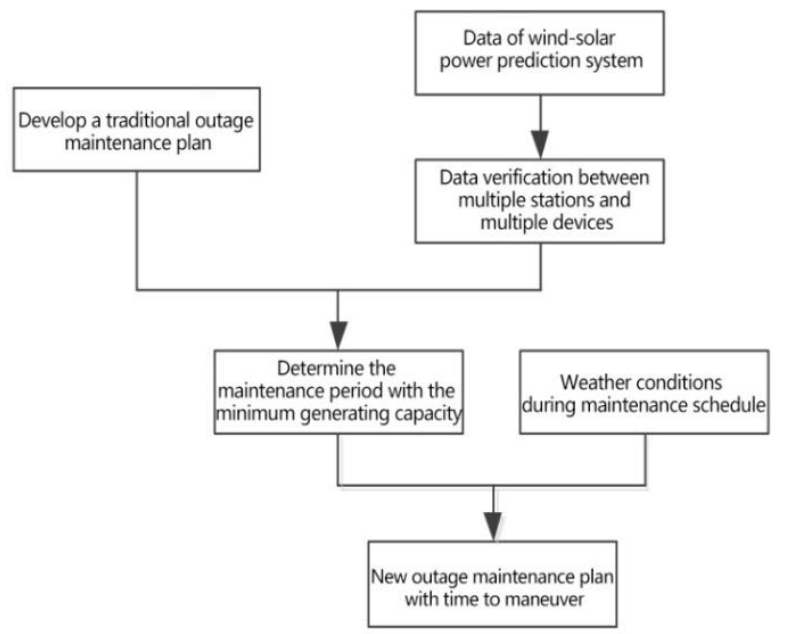

Figure 3. Drawing of company maintenance plan

\subsection{Intelligent operation and maintenance of power generation equipment}

Building intelligence operations system, power plant, operations and maintenance, supplies and training, etc into the system construction, from the management level, digital level and operational level, professional talent training level, material scheduling level and so on carries on the unified planning and design, with new energy intelligence operations platform made of "wisdom mind" and goods, shipment inspection service sharing and efficient platform combines the wisdom of the operating system. Artificial intelligence, big data and cloud computing technologies are utilized to collect and store energy equipment operation and maintenance data and environmental prediction data without adding new sensor detection points, and to establish early warning algorithm to realize early warning of health risks. Through the health management platform and the production system, the closed-loop management of defects is realized, and the transformation from passive maintenance to active preventive maintenance is realized.

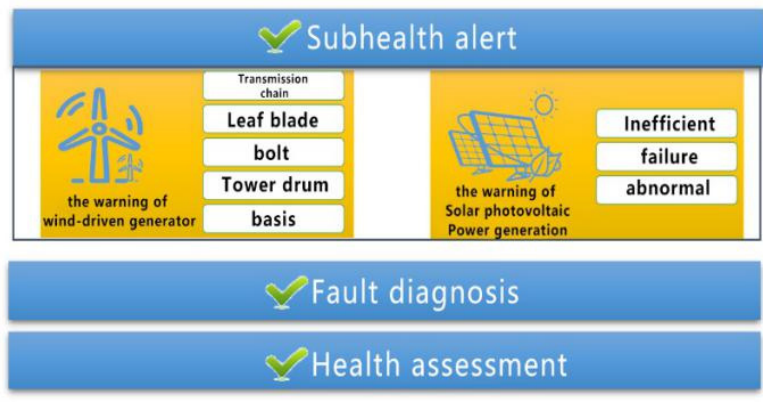

Figure 4. Intelligent operation system diagram

Based on the big data platform, the intelligent inspection system integrates the remote intelligent inspection function, the system realizes the full scene visualization, and carries out real-time monitoring on various on-site devices through SCADA, image, infrared, sound and other technical means, and changes the manual periodic inspection into the active online inspection mode. Through the intelligent application and data mining, operations management of the implementation of new energy has changed from passive to active prevention, and the problems found from extensive operations into refinement operations, to implement the intelligent of the terminal inspection upgrades, reducing the number of inspection, expanding the scope of supervision, reducing degree of difficulty inspection and improving the quality of inspection, improving the efficiency of management, to authors efficiency goals.

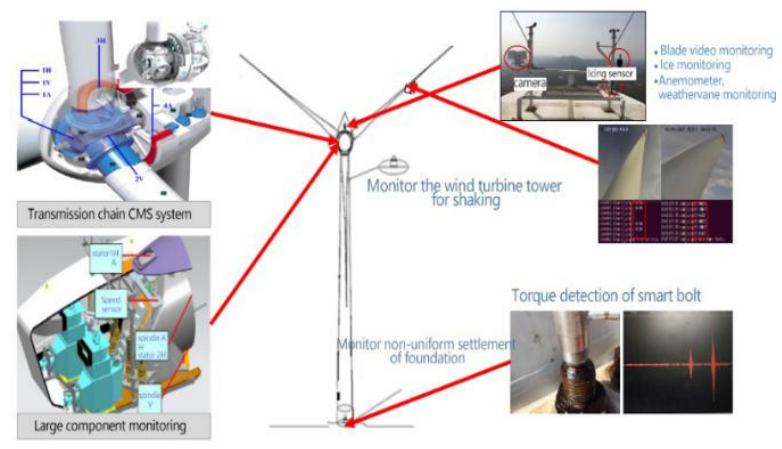

Figure 5. Full scene visual intelligent inspection diagram

\subsection{Intelligent dispatching of power station control}

The active power coordination control function will execute the generation plan, operation mode and AGC instructions issued by the superior dispatching, combined with wind power, photovoltaic power prediction, energy storage energy state to analysis the state of power plant, through the intelligent decision after distributed to the wind power, photovoltaic power station, and energy storage power station terminal control instruction, and then by the terminal monitor system to execute the instruction. At the same time, according to the prediction of wind turbine and photovoltaic active power and the energy state of energy storage battery, the control system automatically realizes the dynamic adjustment of power generation and reports to the higher-level control center. 


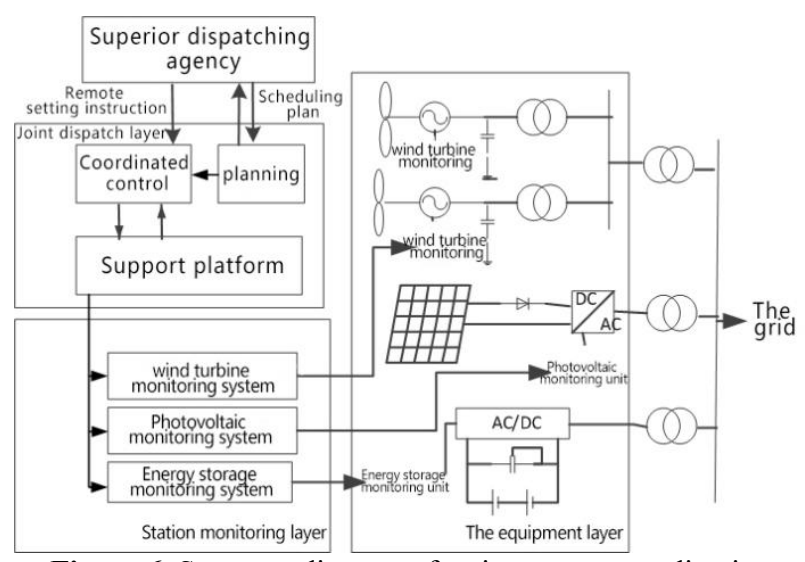

Figure 6. Structure diagram of active power coordination control

The AVC system of the power station monitors and controls the reactive power sources such as wind power plant, PV power station, energy storage power station, SVG and capacitor by acquiring the control model from the network modeling and acquiring the real-time data collected by SCADA, and carries out on-line analysis and calculation. In view of the rapidly changing characteristics of new energy output, the reactive voltage control adopts a hierarchical control framework based on multiple time scales. AVC control aims to meet the operation requirements of $220 \mathrm{kV}$ bus voltage of parallel nodes, which support remote control of the dispatching master station.

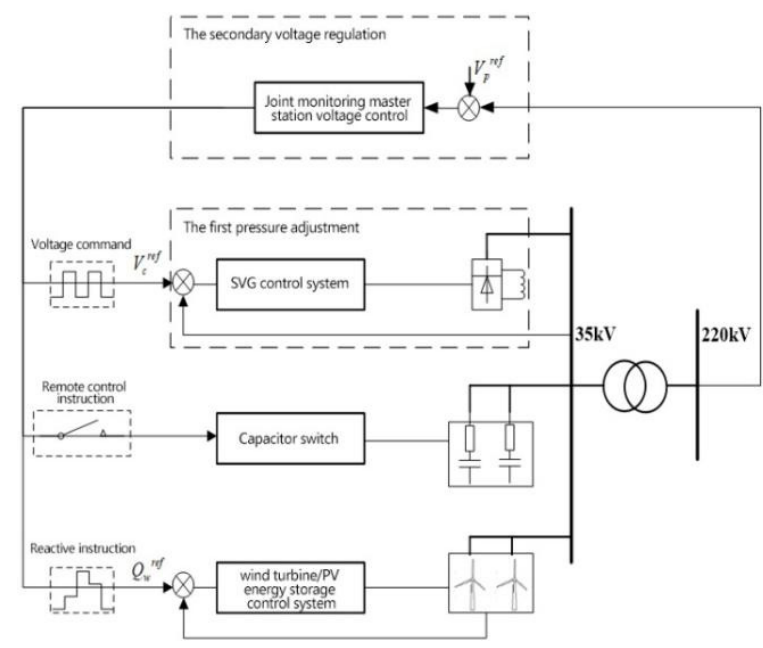

Figure 7. Block diagram of hierarchical voltage control

\subsection{Energy storage applications}

a) Digital application of energy storage battery system

Through the scenery power prediction system, establishing perfect operational system, methods of standards of operation mode, improve the quality of the scenery power generation of electricity, make the new energy power generation predictability, controllability and schedulable on positive input energy storage system adjustment, at the same time will be put into the wind system, optical storage reservoir, reservoir model, in order to meet the interconnection performance requirements or tracking control accuracy. Under each operation mode, due to the different composition of regulating objects, its control objectives will also be different. Therefore, the control mode matching with the mode is designed, which plays a role respectively in smoothing output, tracking plan, system frequency modulation and peak load trimming. In the process of running through the wind, photovoltaic power generation, and in combination with chemical energy storage system, the output of the total in a stable range, effectively improve the quality of the electricity to run online, to solve the impact of wind and solar power on the grid, improve stability and economy of power system operation, thus make originally not easy to control the scenery power generation have like conventional power output characteristics. In addition, considering the channel to be delivered to the outside pressure is larger, the channel is blocked, the positive use of energy storage device which can adjust the charge and discharge, reduced the electricity situation, through the remote command automatic control, to achieve energy storage by other patterns quickly switch to charging mode, after the charge under the condition of no electricity will have a rapid release of energy storage before storing electrical energy and abandon the biggest application of electric power.

b) Digital voice application of electric heating boiler energy storage system

Operations, the majority of new energy, especially wind farm is located in the low temperature area, in parts of the heating time for half a year, construction material consumptions of heat, light of the specific conditions of the base itself, put forward the study applies power brownouts time abandon wind, abandoned by using light power application in the electric heat storage technology renovation project, the base station set up "generation and electric heating flexible adjustment of supply and demand platform". By digitization and automation transformation, the use of electric boiler heating system characteristics of the heat storage tank can be stored, in power brownouts time, start the whole power electric boiler heating, realize power at electricity used for heating, heat accumulation, and heating, increase the wind power, photovoltaic power generation Internet access, in the electricity, will release the heat energy storage for heating, and given some abandoned wind, light power, reduce the consumption of electricity of heating in winter, the effect of saving plant power consumption at the same time, improve channel send capacity, realize mass effect double promotion.

\section{Implementation effect}

First of all, the management level of the enterprise has been significantly improved, and the management quality and safety control ability have been improved. The equivalent utilization hours of equipment ranked first among all new energy stations under the same transmission channel. The utilization rate of wind turbine is over $98 \%$, and that of photovoltaic is more than $99 \%$, both of which are in the leading level of the industry. Secondly, diversified development of enterprise technology achievements, independent development of new energy power station new unified digital monitoring platform, has realized the 5 different manufacturers, seven different wind turbines unified monitoring, technical route 
will be relatively independent of wind turbines into an organic whole, implementation of the unity of all the fan group, group control, realize intelligent operations aided analysis capabilities. Finally, the social value of enterprises is fully demonstrated, which not only serves local economic development, but also makes contributions to the development of new energy industry.

\section{References}

1. Lu. L. M. (2020) Analysis of the current situation and development trend of new energy power generation technology. J. Engineering construction and design, 22: 110-111.

2. Le. W. (2020) Exploration on current situation and future development direction of wind power generation in China under the background of new energy. J. Green and environment-friendly building materials, 11: 165-166.

3. Song. P. F, Tong. S. W, Duan. S. Y. (2019) Analysis on the influence of new energy generation on power quality of power grid. J. Communication power technology, 12: 139-140.

4. Du. M, Ye T, (2019) Influence of new energy grid connection on power quality of power system. J. In the world of digital communications, 07: 144+185.

5. An. X. Y, Zhang L. W, Fan. X. Y, et. al, (2018) Influence of new energy grid connection on power quality of power system. J. Modern industrial economy and information technology, 06: 49$50+53$.

6. Yang. B, (2016) The enlightenment of The Development and application of Foreign new energy power generation Technology to China. J. Horizon of science and technology, 08: 24-25. 2016 